\title{
Spectrophotometric Determination of Trace Cyanide in Fruit Wines by the Catalytic Reaction of Ninhydrin following Micro-distillation
}

\author{
ROMTEERA CHUEACHOT and SAKSIT CHANTHAI* \\ Department of Chemistry and Center of Excellence for Innovation in Chemistry, \\ Faculty of Science, Khon Kaen University, Khon Kaen 40002, Thailand. \\ ${ }^{*}$ Corresponding author E-mail: sakcha2@ @ku.ac.th \\ http://dx.doi.org/10.13005/ojc/300115
}

(Received: December 10, 2013; Accepted: January 17, 2014)

\begin{abstract}
Trace analysis of cyanide $(\mathrm{CN})$ based on the absorbance of the catalytic reaction of ninhydrin $(\mathrm{NH})$ in the presence of $\mathrm{CN}^{-}$was developed. This reaction was investigated consisting of $0.08 \mathrm{M}$ $\mathrm{NH}, 0.4 \mathrm{M} \mathrm{Na}_{2} \mathrm{CO}_{3}, 1 \%(\mathrm{v} / \mathrm{v})$ Tween 20 and $2.5 \mathrm{M} \mathrm{NaOH}$ in $5-\mathrm{mL}$ final volume. The absorbance of the $\mathrm{CN}-\mathrm{NH}$ complex was measured against the reagent blank at $598 \mathrm{~nm}$. The calibration curve was widely linear over the range of $40-160 \mu \mathrm{g} / \mathrm{L}$ with $\mathrm{r}^{2}>0.99$. The method recoveries of free cyanide, bound cyanide and total cyanide for wine samples were found in the range of $76.2-89.2 \%, 73.2-$ $91.2 \%$ and $76.8-94.8 \%$, respectively, at $250 \mu \mathrm{g} / \mathrm{L} \mathrm{CN}-$ spiked level. Limit of detection was $6 \mu \mathrm{g} / \mathrm{L}$. The reproducibility of the proposed method was less than $4.44 \%$. This method was then applied for local Thai fruit wines. No trace amount of cyanide was detected, as if high recovery $(88.4 \%)$ of the microdistillation was guaranteed. The obtained results were in agreement with those of the chloramine-T/ barbituric acid-pyridine method with no statistically significant difference at $95 \%$ confidence level.
\end{abstract}

Key words: Cyanide, Wine, Ninhydrin, Micro-distillation, Chloramine-T/barbituric acid-pyridine.

\section{INTRODUCTION}

Wine is a natural product, widely consumed in the world with thousands years of tradition and has an obvious commercial value ${ }^{1,2}$. Wine, in the broader sense, is beverage resulting from the fermentation by yeast of fruit juice, although it is possible to make them from vegetable, herb and other plants, with appropriate processing and additions ${ }^{3}$. Wines typically have alcohol strength of $8 \%$ to $14 \%$, although fortified wine can go as high as $24 \% 4$. Numerous studies have shown that the moderate consumption of wine, especially red, improves good health and longevity when it is combined with a balanced diet ${ }^{1,5,6}$. 
Nowadays, the increasing global pollution of the environment requires a systematic monitoring of all kinds of foods and drinks including wines. Thus, there may be many sorts of accumulative toxic substances such as cyanide ${ }^{5,7-13}$. Cyanide is one of the most lethal poisons known ${ }^{14}$. In many kinds of cyanide compounds, some are gases, others are solids or liquids. Some are molecular, some ionic, and many are polymeric. Those that can release the $\mathrm{CN}^{-}$, are highly toxic ${ }^{15}$.

Japan's Ministry of Health, Labour \& Welfare has amended the Food Sanitation Law to permit the use of ferrocyanides as food colorants, with the property of preventing salt from "caking". Ferrocyanides are quite widely used for this purpose in salt and processed foods in Australia, China and the USA ${ }^{16}$. Hexacyanoferrate is a common pollutant that may be released into the environment directly or can be indirectly formed when free cyanide $(\mathrm{HCN}$, $\mathrm{CN}^{-}$) is released into water sources that contain iron(II) and iron(III) $)^{11,17 .}$.

The analysis of cyanide has become increasingly important because of high toxicity of the most poison both in its inorganic and organic compounds. The mechanism of human toxicity for cyanide is by absorption ${ }^{14}$. Some indications of cyanide poisoning are rapid, deep breathing and shortness of breath, followed by convulsions and loss of consciousness. These symptoms can occur rapidly, depending on the amount eaten. The health effects of large amounts of cyanide are similar, whether you eat, drink or breath it; cyanide uptake into the body through the skin is slower than those other means of exposure. Skin contact with hydrogen cyanide or cyanide salts can irritate and produce sores $^{12,16}$. All these findings cause a great concern regarding public health, demanding an accurate determination procedure of this cyanide and bound cyanide at either trace or ultra-trace levels.

The most widely used techniques for the quantification of cyanide and cyanide compound are based on standard method ${ }^{19}$. The analytical methods have been published concerning the determination of cyanide including voltammetry, ionselective potentiometry, indirect atomic absorption spectrometry, spectrofluorimetry or molecular absorption spectrophotometry ${ }^{20}$. Chromatographic techniques and capillary electrophoresis seem to be special suitable for very complex matrices ${ }^{21-23}$. A wide range of detection limits for cyanide determinations have been given in such publication. However, while the most sensitive methods reported have to resort to sophisticated systems and procedures, others suffer from instabilities of the reagents used, high cost, lengthy analysis time or lack of selectivity.

Spectrophotometry has widely been used to determine cyanide ${ }^{10,24-29}$. This technique for cyanide analysis is far more superior to other techniques including titrimetric, polarographic, fluorometric, voltammetric and chromatographic methods ${ }^{29}$. These methods have mainly been based on measuring the absorbance of complexing agents due to complexation with cyanide. For example, the effect of cyanide on chloramines-T and barbituric acidpyridine was used for the standard method for the determination of cyanide ${ }^{24,30}$. The standard method is sensitive to cyanide but the complexation with chloramines-T and barbituric acid-pyridine is difficult and expensive for determination of cyanide ${ }^{19}$.

In the present study, a simple and sensitive spectrophotometric method was once subjected to develop and validate for the ultra-trace amount of residual cyanide in wine sample, based on the reaction between cyanide and ninhydrin. The experimental variables affecting color formation and the possible interference of co-existing ions were thoroughly studied. The optimum conditions established were then laid in the recommended procedure. The results were compared to those of standard method. This method was applied for the determination of free and bound cyanide ions in local Thai fruit wine samples.

\section{MATERIALS AND METHODS}

\section{Chemicals and Instruments}

All chemicals used were at least analytical reagent grade. Barbituric acid, mercuric chloride, potassium hydroxide and sodium hydroxide were purchased from Carlo Erba (Italy). Sodium carbonate and sodium dodecyl sulphate were purchased from Ajax FineChem (Australia). Cuprous chloride and potassium hexacyanoferrate were purchased from Laboratory BHD Reagent (England). Ninhydrin was purchased from Fluka BioChemika (India). 
Potassium cyanide, pyridine and sodium hydrogen phosphate were purchased from AnalaR ${ }^{\circledR}$ (England). Chloramine-T was purchased from Fluka Chemika (Netherland). All aqueous solutions were prepared with deionized water (Milli Q Millipore 18.2 MW.cm of resistivity) by Simplicity water purification system, Simplicity 185, Millipore Corporation (USA).

All absorbance measurements were carried out on UV-Visible spectrophotometer (Agilent 8453, Germany) and spectrophotometer (Jenway, UK) equipped with $1.0 \mathrm{~cm}$ quartz cell. All samples were digested with micro-distillation (Small-Lab Kit Standard set, Thailand). The $\mathrm{pH}$ measurements were made with a Denver Instrument $\mathrm{pH}$ meter model 251 (Denver Instrument, USA) with a combined ATC electrode.

\section{Wine samples}

Wine samples, both white and red wines, locally produced from various kinds of typical Thai fruits were purchased from supermarkets and the "OTOP" (One Tumbon One Product) centre in Khon Kaen and other provinces in Thailand including white wine 1 (fruit, Samut Sakhon), white wine 2 (Bengal quince "Matoom", Khon Kaen), white wine 3 (apple, Bangkok), white wine 4 (passion fruit and pineapple, Bangkok), white wine 5 (star gooseberry "Mayom", Khon Kaen), red wine 1 (fruit, Samut Sakhon), red wine 2 (roselle and pineapple, Bangkok), red wine 3 (roselle and pineapple, Chon Buri), red wine 4 (Thai blueberry "Mamow", Loei), and Red wine 5 (jamaice sorrel "Krajeab", Sakon Nakhon).

\section{Micro-distillation optimization for wine sample}

A $12 \%(v / v)$ ethanol solution was prepared by dilution of $12 \mathrm{~mL}$ absolute ethanol to $100 \mathrm{~mL}$ volumetric flask with deionized water. A $10 \%(\mathrm{v} / \mathrm{v})$ $\mathrm{H}_{2} \mathrm{SO}_{4}$ solution was prepared by dilution of 10 $\mathrm{mL}$ conc. $\mathrm{H}_{2} \mathrm{SO}_{4}$ to $100 \mathrm{~mL}$ volumetric flask with deionized water. A $0.1 \mathrm{M} \mathrm{NaOH}$ was prepared by dissolving $1 \mathrm{~g}$ of $\mathrm{NaOH}$ in $500 \mathrm{~mL}$ of deionized water.

An acid-distillation was performed with a micro-distillation apparatus standing in hood. The apparatus consist of digestion and absorber units. The optimum conditions for the preparation of cyanide were studied by micro-distillation. The parameters affected on the absorbance were investigated. The effect of reducing agent was investigated by varying the type of reducing agent such as $\mathrm{CuCl}, \mathrm{CuSO}_{4}$ and $\mathrm{SnCl}_{2}$. The effect of acid type was investigated by varying the type of an acid used including $\mathrm{H}_{2} \mathrm{SO}_{4}, \mathrm{HNO}_{3}, \mathrm{H}_{3} \mathrm{PO}_{4}, \mathrm{HCl}$ and $\mathrm{HClO}_{4}$. The effect of temperature was investigated by varying the temperature for digestion from $60{ }^{\circ} \mathrm{C}$ to $110^{\circ} \mathrm{C}$. The effect of distillation time was investigated by varying the time for digestion from $15 \mathrm{~min}$ to 2 h. The effect of sample volume was investigated by varying the sample volume from $5 \mathrm{~mL}$ to 15 $\mathrm{mL}$ according to limited volume of the micro-round bottom flask.

\section{Determination of cyanide by the catalytic reaction of ninhydrin}

A $1000 \mathrm{mg} / \mathrm{L}$ standard solution of cyanide ion was prepared by dissolving $0.6030 \mathrm{~g}$ of potassium cyanide in $250 \mathrm{~mL}$ deionized water. A $1000 \mathrm{mg} / \mathrm{L}$ standard solution of ferrocyanide was also prepared by dissolving $4.0960 \mathrm{~g}$ of potassium ferrocyanide in $250 \mathrm{ml}$ deionized water. A serial dilution of cyanide or ferrocyanide was freshly prepared from the stock cyanide solution of $100 \mathrm{mg} / \mathrm{L}$ with deionized water prior to use. A $0.08 \mathrm{~mol} / \mathrm{L}$ ninhydrin was prepared by dissolving $7.1256 \mathrm{~g}$ of ninhydrin in $500 \mathrm{~mL}$ deionized water. A $0.4 \mathrm{M} \mathrm{Na}_{2} \mathrm{CO}_{3}$ was prepared by dissolving $15.9990 \mathrm{~g}$ of $\mathrm{Na}_{2} \mathrm{CO}_{3}$ in $250 \mathrm{~mL}$ deionized water. A $2.5 \mathrm{M} \mathrm{NaOH}$ was prepared by dissolving $49.9962 \mathrm{~g}$ of $\mathrm{NaOH}$ in $500 \mathrm{~mL}$ of deionized water. A $1 \%(\mathrm{v} / \mathrm{v})$ Tween 20 was prepared by dilution $2.5 \mathrm{~mL}$ of Tween 20 to $250 \mathrm{~mL}$ volumetric flask with deionized water.

The calibration curve was established using the standard solution prepared in deionized water by dilution from the stock solution of free cyanide. This standard solution was not introduced through the preparation procedure. An aliquot of a standard solution containing 0.1-1.6 $\mathrm{mg}$ of cyanide was transferred in to a series of $5 \mathrm{~mL}$ volumetric flask, to which $0.8 \mathrm{~mL}$ of $0.08 \mathrm{~mol} / \mathrm{L}$ ninhydrin and $0.8 \mathrm{~mL}$ of $0.4 \mathrm{~mol} / \mathrm{L} \mathrm{Na}_{2} \mathrm{CO}_{3}$ were added; the solution was kept aside for about $30 \mathrm{~min}$ for completion of the reaction to give a deep-red color, then added $0.4 \mathrm{~mL}$ of $1 \%(\mathrm{v} / \mathrm{v})$ Tween 20 as micellar media and diluted to mark with $2.5 \mathrm{M} \mathrm{NaOH}$. The deep-blue color was kept aside about 30 min for complex stability. After mixing the solutions, aliquots of each solution were determined by a spectrophotometer. 
Factors affecting the catalytic reaction of the cyanide-ninhydrin complex

The optimum conditions for the determination of cyanide based on absorbance using ninhydrin were studied. The parameters affected on the absorbance were investigated. The effect of the $\mathrm{pH}$ of buffer solution was studied in the range from 2.0 to 12.0 with carbonate buffer solution. The anion buffering systems were investigated including $\mathrm{CH}_{3} \mathrm{COO}, \mathrm{SO}_{4}^{2-}$, $\mathrm{HPO}_{4}{ }^{2-}$ and $\mathrm{PO}_{4}{ }^{3-}$. The cation systems were also studied such as $\mathrm{K}^{+}, \mathrm{Na}^{+}$and $\mathrm{Li}^{+}$.

The effect of ninhydrin concentration was studied in the range of 0.0 to $0.10 \mathrm{M}$. The effect of $\mathrm{Na}_{2} \mathrm{CO}_{3}$ concentration was studied in range from 0.0 to $1.0 \mathrm{M}$. The effect of $\mathrm{NaOH}$ concentration was investigated using $\mathrm{NaOH}$ at the concentrations ranging from 1.0 to $3.0 \mathrm{M}$. The effect of micellar medium was studied by varying the type of micellar media such as Triton-X 100, hexadecyltrimethyl ammonium bromide (CTAB), sodium dodecyl sulphate (SDS) and Tween 20. The effect of Tween 20 concentration was investigated by varying the volume of $1 \%(\mathrm{v} / \mathrm{v})$ Tween 20 from 50 to $500 \mu \mathrm{L}$. The effect of mixing sequence was evaluated by varying several sequences of reagent addition. The effect of reaction time was investigated by varying the reaction time for complete reaction from 0 to $3 \mathrm{~h}$. The effect of interfering ions (cations and anions) was studied individually to investigate their adverse effect, if any, on the determination of $0.12 \mathrm{mg} / \mathrm{L}$. Cations were added as $\mathrm{Na}^{+}, \mathrm{K}^{+}, \mathrm{Ag}^{+}, \mathrm{Ca}^{2+}, \mathrm{Mg}^{2+}, \mathrm{Cd}^{2+}, \mathrm{Fe}^{2+}, \mathrm{Hg}^{2+}$, $\mathrm{Mn}^{2+}, \mathrm{Al}^{3+}$ and $\mathrm{Fe}^{3+}$. Anions were added as $\mathrm{Cl}^{-}, \mathrm{F}^{-}, \mathrm{I}^{-}$, $\mathrm{NO}_{3}, \mathrm{SO}_{4}^{2-}, \mathrm{Fe}(\mathrm{CN})_{6}^{3-}$ and $\mathrm{Fe}(\mathrm{CN})_{6}^{4-}$.

\section{Determination of cyanide by chloramine-T/ barbituric acid-pyridine}

Preparation of $0.2 \mathrm{M}$ potassium hydrogen phthalate buffer, $\mathrm{pH} 4.8$ was done. A $40.85 \mathrm{~g}$ potassium hydrogen phthalate was dissolved in $1 \mathrm{~L}$ with deionized water and adjusted to $\mathrm{pH} 4.8$ by a drop rise of $1 \mathrm{M} \mathrm{HCl}$. Preparation of $0.2 \mathrm{M}$ chloramine- $\mathrm{T}$ solution was also done. A $0.25 \mathrm{~g}$ chloramine-T was filled up with deionized water to $50 \mathrm{~mL}$. The solution was freshly prepared every day. Preparation of barbituric acid-pyridine solution was done. A 1.75 $\mathrm{g} \mathrm{NaOH}$ was dissolved in about $125 \mathrm{~mL}$ deionized water. A $4.2 \mathrm{~g}$ barbituric acid and $3.4 \mathrm{~g}$ pyridine were added and stirred for $30 \mathrm{~min}$. The solution was filled up with deionized water to $250 \mathrm{~mL}$. The solution was prepared weekly and protected from light.

The calibration curve was established using the standard solution of $\mathrm{CN}^{-}$prepared in deionized water by dilution from the working solution of cyanide $(10.0 \mathrm{mg} / \mathrm{L})$. The series of the standard solution was $0.2,0.4,0.6,0.8,1.0$ and $1.2 \mathrm{mg} / \mathrm{L}$, respectively. The standard solutions were preceded through the chloramines-T/barbituric acid-pyridine complex reaction and determined by spectrophotometry at 600 $\mathrm{nm}$. The analytical characteristics of the proposed method for cyanide analysis were investigated under the optimum conditions. The studied parameters were linearity, limit of detection (LOD), limit of quantitation (LOQ), precision and accuracy.

Linearity was obtained from calibration plot. The calibration plots were studied by analysis of the standard mixture with various concentrations ranging from 0.04 to $0.16 \mathrm{mg} / \mathrm{L}$ of cyanide. LOD and $L O Q$ of the proposed method were deduced based on the signal to noise ratio $(\mathrm{S} / \mathrm{N})$ of 3 and 10 , respectively. The accuracy of the proposed method was expressed in terms of recovery. The recovery was studied by spiking a known concentration of standard into samples before analysis in three replicates. The recovery study of cyanide analysis was performed based on an absorbance. The cyanide at the concentration of $250 \mu \mathrm{g} / \mathrm{L}$ was spiked into the samples. The precision of the present method was evaluated in terms of reproducibility and repeatability of the calibration slope. The relative standard deviation (RSD) is the target value for quantitation. The repeatability (intra-day precision) was achieved by replicating measurements of the calibration slope in a day $(n=3)$ whereas, reproducibility (inter-day precision) was calculated from the experiments carried out in five consecutive days $(n=5)$.

\section{RESULTS AND DISCUSSION}

\section{Micro-distillation of the cyanide sample}

An experimental work was carried out in order to optimize micro-distillation condition for the preparation of cyanide. The following micro-distillation parameters were reducing agent, temperature, time, acidic type and sample volume. A reducing agent is the element or a compound in a reduction-oxidation reaction that reduces another species. In doing so, it becomes oxidized, and is therefore the electron 
donor in the redox system. The reducing agent in this reaction is ferrocyanide, it donates an electron, converting to ferricyanide, simultaneously with the reduction of chlorine to chloride. So, the effect of reducing agents on the sample preparation by microdistillation was studied in the presence of reducing agents including none, $\mathrm{SnCl}_{2}, \mathrm{CuCl}$ and $\mathrm{CuSO}_{4}$. Based on absorbance, comparison of absorbance showed difference in the reducing agents as shown in Fig. 1. Hence, $0.001 \mathrm{~g}$ of $\mathrm{CuCl}$ was found to give the maximum absorbance of the product for free and bound cyanide.

The important conditions for free and bound cyanide preparation were established. The reducing $\mathrm{CuCl}$ gave chloride ion. This ion reacted with ferrocyanide or bound cyanide. Thus, the reaction of the complex of both gave free $\mathrm{CN}^{-}$in an acidic solution. The distillation temperature based on the absorbance of free and bound cyanide is shown in Fig. 2. In this case, the absorbance increased from 0.13 up to 2.3 and 0.094 up to 2.3 for free and bound cyanide, respectively, when the temperature of the distillation unit increased from 60 to $100^{\circ} \mathrm{C}$. However, it boiled at $110^{\circ} \mathrm{C}$ and the absorbance of the cyanide product decreased. Therefore, the distillation temperature of $100^{\circ} \mathrm{C}$ was found to be considerably suitable.

The result of this experiment is shown in Fig. 3. For all samples the cyanide content clearly depended on distillation time. In the range from $15 \mathrm{~min}$ to $1 \mathrm{~h}$ the cyanide content increased continuously. A prolonged distillation time above $2 \mathrm{~h}$ did not result in an increasing of the cyanide contents. The cyanide contents remained more or less constant indicating that the distillation time was completed after $1 \mathrm{~h}$. The acid digestion method laid down in Germany underestimates total cyanide in samples when using a distillation time of $1 \mathrm{~h}^{30}$. In the following, all samples were performed using a distillation time of $1 \mathrm{~h}$.

Table 1: Recovery of free and bound cyanide in a model solution taken by micro-distillation and determined by the developed method (mean $\pm S D, n=3$ )

\begin{tabular}{lcccc}
\hline Species & CN- taken $(\boldsymbol{\mu g} / \mathrm{L})$ & $\mathrm{CN}^{-}$found $(\boldsymbol{\mu g} / \mathrm{L})$ & RSD (\%) & Recovery (\%) \\
\hline \multirow{2}{*}{$\mathrm{KCN}$} & 100 & 84 & 23.6 & $84 \pm 0.08$ \\
& 200 & 176 & 7.35 & $88 \pm 0.06$ \\
& 500 & 445 & 1.51 & $89 \pm 0.03$ \\
$\mathrm{~K}_{4}\left[\mathrm{Fe}(\mathrm{CN})_{6}\right]$ & 100 & 80 & 6.09 & $80 \pm 0.02$ \\
& 200 & 164 & 1.05 & $82 \pm 0.08$ \\
& 500 & 440 & 0.56 & $88 \pm 0.01$ \\
\hline
\end{tabular}

Table 2: Table 2: Recovery of different levels of spiked cyanide in wine samples taken by micro-distillation and determined by the developed method (mean $\pm S D, n=3$ )

\begin{tabular}{lcccc}
\hline \multirow{2}{*}{ Species } & CN' taken $(\mu \mathrm{g} / \mathrm{L})$ & $\mathbf{C N}^{-}$found $(\boldsymbol{\mu g} / \mathrm{L})$ & RSD (\%) & Recovery (\%) \\
\hline \multirow{2}{*}{ White wine } & 100 & 82 & 0.146 & $82.0 \pm 0.12$ \\
& 200 & 171 & 0.508 & $85.5 \pm 0.87$ \\
& 300 & 261 & 0.536 & $87.0 \pm 1.40$ \\
Red wine & 400 & 340 & 0.262 & $85.0 \pm 0.89$ \\
& 500 & 442 & 0.443 & $88.4 \pm 1.96$ \\
& 100 & 80 & 1.550 & $80.5 \pm 1.24$ \\
& 200 & 169 & 0.402 & $84.5 \pm 0.76$ \\
& 300 & 256 & 0.636 & $85.3 \pm 1.82$ \\
& 400 & 332 & 0.250 & $83.0 \pm 0.94$ \\
& 500 & 432 & 0.464 & $86.4 \pm 2.17$ \\
\hline
\end{tabular}


Table 3: Effect of foreign ions on the spectrophotometric determination of cyanide

(0.12 $\mathrm{mg} / \mathrm{L})$; tolerance error $\pm 2 \%$

\begin{tabular}{lc}
\hline Species & Tolerance limit $(\mu \mathrm{g} / \mathrm{mL})$ \\
\hline $\mathrm{Na}^{+}$ & 5000 \\
$\mathrm{Mg}^{2+}, \mathrm{I}, \mathrm{NO}_{3}^{-}, \mathrm{Fe}(\mathrm{CN})_{6}^{4-}$ & 4000 \\
$\mathrm{Al}^{3+}, \mathrm{Mn}^{2+}$ & 500 \\
$\mathrm{Fe}^{2+}, \mathrm{K}^{+}, \mathrm{Cd}^{2+}, \mathrm{F}^{-}$ & 100 \\
$\mathrm{Fe}^{3+}$ & 50 \\
$\mathrm{Ca}^{2+}, \mathrm{Fe}(\mathrm{CN})_{6}{ }^{3-}, \mathrm{Cl}^{-}$ & 10 \\
$\mathrm{SO}_{4}{ }^{2-}$ & 5 \\
$\mathrm{Ag}^{+}, \mathrm{Hg}^{2+}$ & 1 \\
\hline
\end{tabular}

The sample preparation by micro-distillation method was also important for free and bound cyanide. The distillation solution has the $\mathrm{pH}$ in range of 2.0-6.0 as the acidic condition ${ }^{10,22}$. In the study, the effect of acidic type on the preparation method by micro-distillation was studied in the presence of various acids including none, $\mathrm{H}_{2} \mathrm{SO}_{4}, \mathrm{HNO}_{3}, \mathrm{HPO}_{3}$, $\mathrm{HCl}$ and $\mathrm{HClO}_{4}$. The result of the acidic type on the absorbance of the cyanide complex is shown in Fig. 4. Hence, a $1 \mathrm{~mL}$ of $10 \%(\mathrm{v} / \mathrm{v}) \mathrm{H}_{2} \mathrm{SO}_{4}$ was used thought out the experiment.

When the conditions for cyanide preparation were established, the sample volume has significant

Table 4: Precision of the developed method expressed as RSD of the slope of intra-day and inter-day data

\begin{tabular}{lll}
\hline $\begin{array}{l}\text { No. of } \\
\text { calibration } \\
\text { graph }\end{array}$ & $\begin{array}{l}\text { Intra-day }(\boldsymbol{n}=\mathbf{3}) \\
\text { Linear equation }\end{array}$ & $\begin{array}{l}\text { Inter-day }(\boldsymbol{n}=\mathbf{5}) \\
\text { Linear equation }\end{array}$ \\
\hline 1 & & \\
2 & $\mathrm{Y}=8.395 \mathrm{X}-0.0845$ & $\mathrm{Y}=8.1875 \mathrm{X}-0.0330$ \\
3 & $\mathrm{Y}=8.510 \mathrm{X}-0.0830$ & $\mathrm{Y}=8.3600 \mathrm{X}-0.0565$ \\
4 & $\mathrm{Y}=8.365 \mathrm{X}-0.0535$ & $\mathrm{Y}=8.3950 \mathrm{X}-0.0845$ \\
5 & & $\mathrm{Y}=8.7275 \mathrm{X}-0.1125$ \\
$\mathrm{RSD}(\%)$ & 0.91 & $\mathrm{Y}=8.7350 \mathrm{X}-0.1105$ \\
\end{tabular}

Table 5: Recovery study of free, bound and total cyanide (each $250 \mu \mathrm{g} / \mathrm{L}$ ) spiked in real wine samples and determined by the developed method (mean $\pm \mathrm{SD}, n=3$ )

\begin{tabular}{|c|c|c|c|}
\hline \multirow[t]{2}{*}{ Sample code } & \multicolumn{3}{|c|}{ Recovery (\%) } \\
\hline & Free cyanide* & Bound cyanide & Total cyanide ${ }^{\star * \star}$ \\
\hline \multicolumn{4}{|l|}{ White wine } \\
\hline WW1 & $88.2 \pm 3.73$ & $91.2 \pm 0.44$ & $94.8 \pm 1.78$ \\
\hline WW2 & $76.6 \pm 3.33$ & $79.2 \pm 2.33$ & $81.2 \pm 1.53$ \\
\hline WW3 & $79.0 \pm 3.47$ & $78.0 \pm 2.89$ & $79.6 \pm 2.72$ \\
\hline WW4 & $87.0 \pm 2.91$ & $86.4 \pm 4.68$ & $91.2 \pm 2.44$ \\
\hline WW5 & $89.2 \pm 3.52$ & $84.8 \pm 2.21$ & $90.8 \pm 2.45$ \\
\hline \multicolumn{4}{|l|}{ Red wine } \\
\hline RW1 & $76.2 \pm 1.61$ & $74.8 \pm 1.63$ & $77.2 \pm 3.62$ \\
\hline RW2 & $82.2 \pm 2.77$ & $83.6 \pm 1.91$ & $86.8 \pm 1.73$ \\
\hline RW3 & $83.4 \pm 3.19$ & $84.4 \pm 3.01$ & $88.4 \pm 3.07$ \\
\hline RW4 & $77.0 \pm 2.91$ & $73.2 \pm 0.84$ & $76.8 \pm 3.15$ \\
\hline RW5 & $78.8 \pm 2.12$ & $77.2 \pm 3.63$ & $80.4 \pm 3.19$ \\
\hline
\end{tabular}


effect on the absorbance of the $\mathrm{CN}^{-}$complex. The decrease in the absorbance with respect to the sample volume can be evaluated by measuring the absorbance of cyanide complex with their different sample volumes. It was found that the absorbance of $\mathrm{CN}^{-}$complex decreased with the increasing sample volume in the range of 5 to $20 \mathrm{~mL}$. This may be affected from the volume of round bottom vessel. Thus, the sample volume of $5 \mathrm{~mL}$ was practically chosen.

\section{Recovery study of a model solution}

A micro-distillation apparatus was aimed to develop to use small sample quantity for the determination of cyanide. The recovery of free cyanide was done by adding various amounts of known cyanide to fixed volume of model solution. The percentage recovery of the both free and bound cyanide is shown in Table 1.

\section{Standard addition}

For the comparison purpose, the cyanide recovery (\%) prepared by the micro-distillation apparatus was determined using a contaminated wine sample containing five levels of the cyanide concentrations. The recovery of cyanide in white wine and red wine was found in range of 82.0 $88.4 \%$ and $80.5-86.4 \%$, respectively as shown in Table 2. The sample matrices that were evaluated showed no apparent interference for the total cyanide determination.

Table 6: Precision of the standard method expressed as RSD of the slope of intra-day and inter-day data

\begin{tabular}{lll}
\hline $\begin{array}{l}\text { No. of } \\
\text { calibration } \\
\text { graph }\end{array}$ & $\begin{array}{l}\text { Intra-day }(\boldsymbol{n}=\mathbf{3}) \\
\text { Linear equation }\end{array}$ & $\begin{array}{l}\text { Inter-day }(\boldsymbol{n}=5) \\
\text { Linear equation }\end{array}$ \\
\hline 1 & $\mathrm{Y}=0.9172 \mathrm{X}+0.0148$ & $\mathrm{Y}=0.9119 \mathrm{X}+0.0352$ \\
2 & $\mathrm{Y}=0.9136 \mathrm{X}+0.0193$ & $\mathrm{Y}=1.0123 \mathrm{X}+0.0349$ \\
3 & $\mathrm{Y}=0.9194 \mathrm{X}+0.0117$ & $\mathrm{Y}=0.9172 \mathrm{X}+0.0148$ \\
4 & & $\mathrm{Y}=0.9376 \mathrm{X}+0.0201$ \\
5 & & $\mathrm{Y}=0.9114 \mathrm{X}+0.0220$ \\
$\mathrm{RSD}(\%)$ & 0.32 & 4.57 \\
\hline
\end{tabular}

Table 7: Recovery study of free, bound and total cyanide (each $250 \mu \mathrm{g} / \mathrm{L}$ ) spiked in real wine samples and determined by standard method (mean $\pm S D, n=3$ )

\begin{tabular}{|c|c|c|c|}
\hline \multirow[t]{2}{*}{ Sample code } & \multicolumn{3}{|c|}{ Recovery (\%) } \\
\hline & Free cyanide $^{*}$ & Bound cyanide ${ }^{* *}$ & Total cyanide $^{\star \star \star}$ \\
\hline White wineWW1 & $85.8 \pm 0.22$ & $90.7 \pm 0.31$ & $92.9 \pm 0.22$ \\
\hline WW 2 & $76.3 \pm 1.89$ & $79.7 \pm 1.40$ & $81.4 \pm 0.67$ \\
\hline WW 3 & $77.4 \pm 0.72$ & $77.6 \pm 0.76$ & $78.4 \pm 1.06$ \\
\hline WW 4 & $87.1 \pm 1.68$ & $86.1 \pm 2.17$ & $91.6 \pm 3.23$ \\
\hline WW 5 & $89.4 \pm 2.31$ & $85.0 \pm 3.06$ & $89.2 \pm 3.23$ \\
\hline \multicolumn{4}{|l|}{ Red wine } \\
\hline RW 1 & $75.4 \pm 1.42$ & $75.2 \pm 2.68$ & $75.1 \pm 2.01$ \\
\hline RW 2 & $81.0 \pm 1.61$ & $83.1 \pm 1.76$ & $86.4 \pm 2.47$ \\
\hline RW 3 & $88.1 \pm 1.18$ & $84.1 \pm 4.76$ & $87.5 \pm 1.45$ \\
\hline RW 4 & $77.4 \pm 1.64$ & $73.9 \pm 1.63$ & $76.6 \pm 3.01$ \\
\hline RW 5 & $76.9 \pm 1.63$ & $76.8 \pm 3.17$ & $80.5 \pm 1.75$ \\
\hline
\end{tabular}


Since sample preparation of cyanide ion was carried out by micro-distillation method, the objective of the preparation step included the removal of interferences and the conversion of the cyanide species to $\mathrm{HCN}$ under distillation conditions. The micro-distillation conditions consisted of $0.001 \mathrm{~g} \mathrm{CuCl}$ as reducing agent, $100^{\circ} \mathrm{C}$ distillation temperature, 1 h distillation time, $1 \mathrm{~mL}$ of $10 \%(\mathrm{v} / \mathrm{v}) \mathrm{H}_{2} \mathrm{SO}_{4}$ and $5 \mathrm{~mL}$ sample volume.

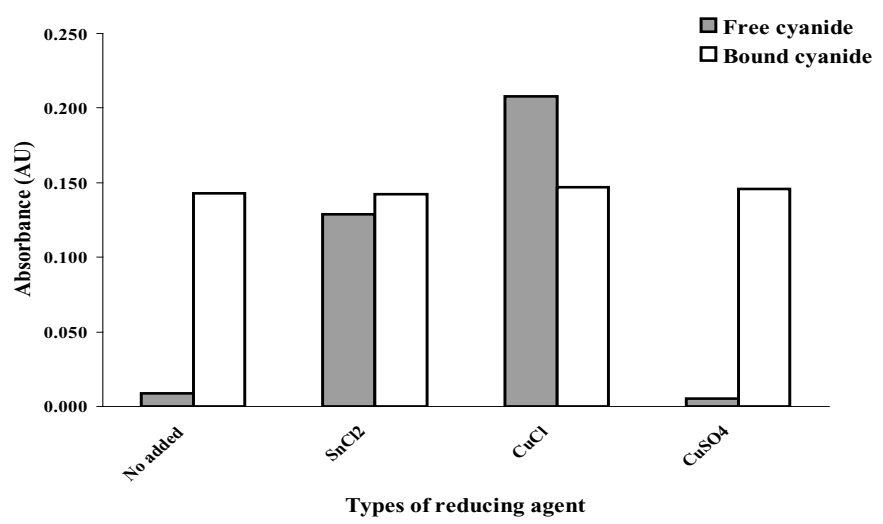

Fig. 1: Effect of reducing agents on the absorbance of free and bound cyanide complex $(n=3)$.

Conditions; temperature $90{ }^{\circ} \mathrm{C}, 30 \mathrm{~min}$ distillation time and $1 \mathrm{~mL}$ of $10 \%(\mathrm{v} / \mathrm{v}) \mathrm{H}_{2} \mathrm{SO}_{4}$

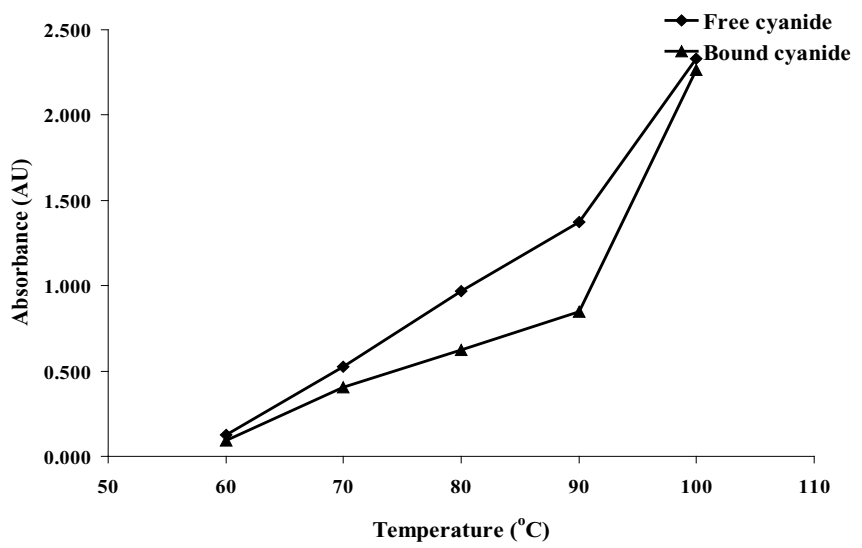

Fig. 2: Effect of distillation temperature on the absorbance of free and bound cyanide complex $(n=3)$. Conditions; $0.001 \mathrm{~g} \mathrm{CuCl}, 30 \mathrm{~min}$ distillation time and $1 \mathrm{~mL}$ of $10 \%(\mathrm{v} / \mathrm{v}) \mathrm{H}_{2} \mathrm{SO}_{4}$

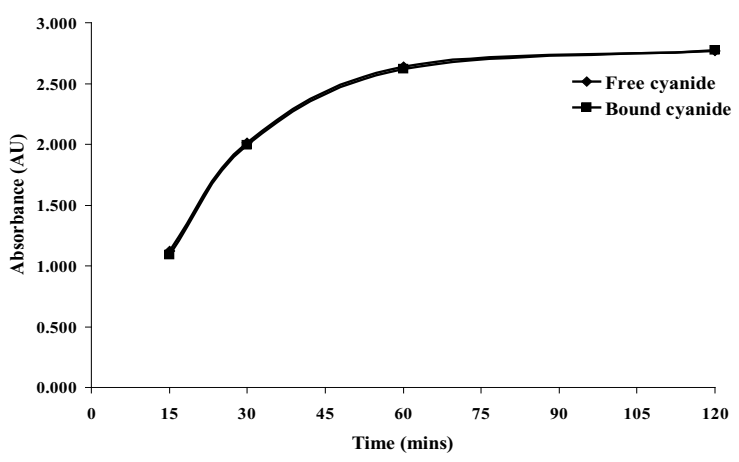

Fig. 3: Effect of distillation time on the absorbance of free and bound cyanide complex ( $n=3)$. Conditions; $0.001 \mathrm{~g} \mathrm{CuCl}$, temperature $100 \stackrel{\circ}{\circ}$ and $1 \mathrm{~mL}$ of $10 \%(\mathrm{v} / \mathrm{v}) \mathrm{H}_{2} \mathrm{SO}_{4}$ 
Determination of cyanide by its cyanide-ninhydrin complex method

In order to determine the optimum conditions for cyanide determination based on the absorbance using ninhydrin, the parameters affecting the absorbance were studied. Ninhydrin reacts with cyanide ion in an aqueous medium to form hydrindantin, which decomposes in the presence of $\mathrm{Na}_{2} \mathrm{CO}_{3}$ to give a red colored product which has a maximum absorbance at $495 \mathrm{~nm}$. When $\mathrm{NaOH}$ was added to the red colored solution, an intense blue colored product was obtained with a strong bathochromic shift of $495 \mathrm{~nm}$ to $598 \mathrm{~nm}$ with increased absorbance. Hence, $598 \mathrm{~nm}$ was used for all subsequent measurements. The absorption spectra of this product and the reagent blank are shown in Fig. 5. When ninhydrin was added to $\mathrm{Na}_{2} \mathrm{CO}_{3}$ solution, it gave a yellow color. This yellow color disappeared after adding $\mathrm{NaOH}$. Hence, the absorption spectrum of the blue colored product was taken against a yellow colored reagent blank for comparison purpose. Thus the absorption at the wavelength of $598 \mathrm{~nm}$ was selected as an optimum experimental wavelength throughout the study.

$\mathrm{pH}$ is an important parameter because the formation of cyanide complex with ninhydrin system is $\mathrm{pH}$-dependent. Thus, the effect of $\mathrm{pH}$ of the buffer solution on absorbance was evaluated in the range from 2.0-12.0 with carbonate buffer solution. It was found that the highest absorbance was obtained when the cyanide-ninhydrin was added to $\mathrm{Na}_{2} \mathrm{CO}_{3}$ solution (red color) in the $\mathrm{pH}$ range of 10.0-12.0. When the red color solution was added to $\mathrm{NaOH}$ solution, it became blue color. The highest absorbance of the blue color solution was obtained.

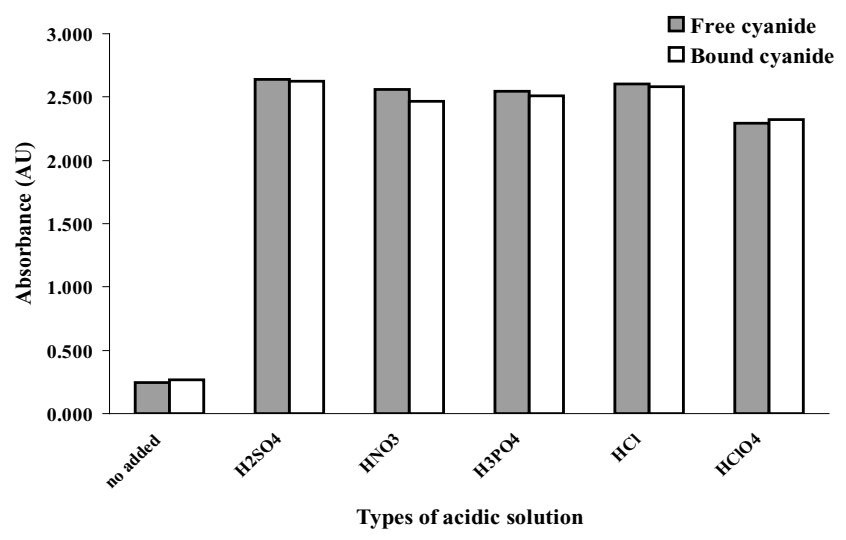

Fig. 4: Effect of acid type on absorbance of the cyanide complex $(n=3)$. Conditions; $0.001 \mathrm{~g} \mathrm{CuCl}$, temperature $100^{\circ} \mathrm{C}$ and $1 \mathrm{~h}$ distillation time

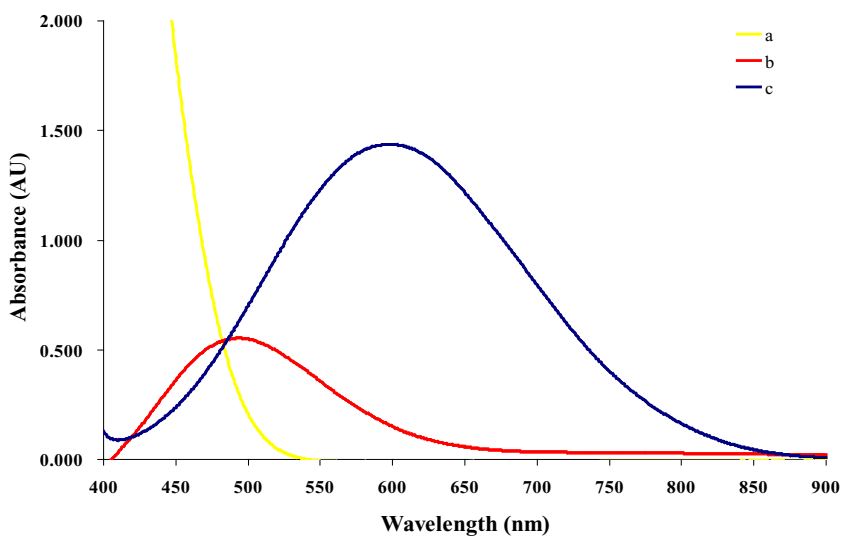

Fig. 5: bsorption spectra of the reaction mixture (a) $\mathrm{NH}+\mathrm{Na}_{2} \mathrm{CO}_{3} \rightarrow$ (yellow), (b) $\mathrm{CN}^{-}+\mathrm{NH}+$ $\mathrm{Na}_{2} \mathrm{CO}_{3} \rightarrow$ (red) and (c) $\mathrm{CN}^{-}+\mathrm{NH}+\mathrm{Na}_{2} \mathrm{CO}_{3}+\mathrm{NaOH} \rightarrow$ (blue). Final concentration of $\mathrm{CN}: 0.12 \mathrm{mg} / \mathrm{L}$ 
Five different anions were studied including carbonate, acetate, sulphate, hydrogen phosphate and phosphate ions. The carbonate anion gave the highest absorbance. Also three different cations were studied including potassium, sodium and lithium ions. The sodium cation gave the highest absorbance. In this study, cyanide ion can act as a specific base catalyte. Hence, the sodium carbonate and sodium hydroxide were used for the experiment.

The ninhydrin concentration was optimized for the cyanide-ninhydrin complex formation. The effect of ninhydrin concentration on the absorbance was studied using various concentrations of ninhydrin from $0.0-0.10 \mathrm{M}$. The results showed that a proper increase in the ninhydrin concentration enhances the absorbance as shown in Fig. 6. It is shown that the maximum absorbance occurred when the concentration of ninhydrin varied over the range 0.06-0.10 M. However, in considering the consistent

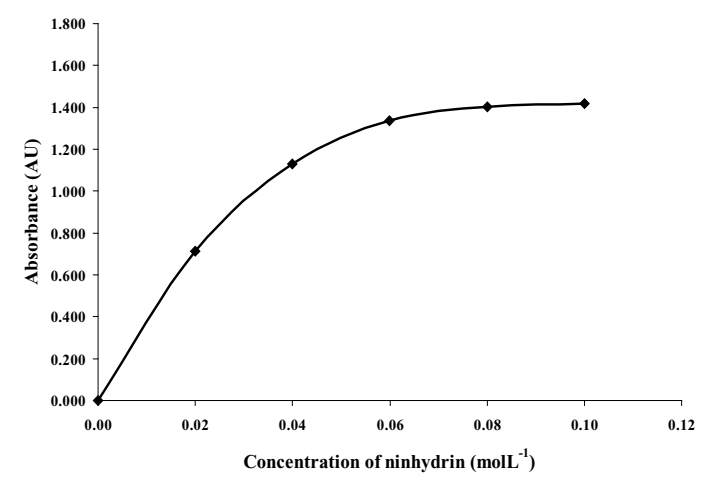

Fig. 6: Effect of ninhydrin concentrations on the absorbance. Final concentration of $\mathrm{CN}: 0.12 \mathrm{mg} / \mathrm{L}$

is shown that the absorbance remained comparably with various concentrations of sodium hydroxide. On the other hand, the optimum conditions were obtained at between 1.0 and $2.5 \mathrm{M}$ of sodium hydroxide. But in the range of $1.0-2.0 \mathrm{M}$ it might be the instability of the complex. Therefore, $2.5 \mathrm{M}$ of sodium hydroxide was found to give the maximum absorbance yielding stability of the complex product.

The influence of reaction time on the complex formation based on absorbance was investigated. Constant absorbance values were obtained for $30 \mathrm{~min}$ after adding sodium carbonate manipulation, an addition of $0.08 \mathrm{~mol} / \mathrm{l}$ ninhydrin was enough.

The effect of sodium carbonate was studied using a fixed cyanide concentration. Various concentrations of sodium carbonate were tried, and the results were obtained from 0.0-1.0 M. This shows that an increasing in the sodium carbonate concentration increases the absorbance as shown in Fig. 7. It is shown that the absorbance increased when the concentration of sodium carbonate increased from 0.0-0.4 M. Nevertheless, the absorbance decreased when the concentration of sodium carbonate varied over the range of 0.4-1.0 $\mathrm{M}$. Therefore, $0.4 \mathrm{M}$ of sodium carbonate was chosen for further studies.

The effect of sodium hydroxide concentration on the absorbance was studied using various concentrations of sodium hydroxide from 1.0-3.0 M. It

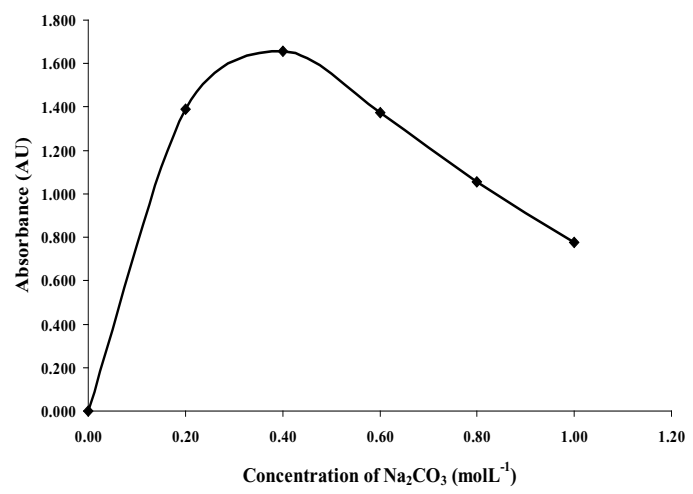

Fig. 7: Effect of various concentrations of sodium carbonate on the absorbance. Final concentration of $\mathrm{CN}: 0.12 \mathrm{mg} / \mathrm{L}$

solution into the ninhydrin-cyanide mixture, and remained stable for $3 \mathrm{~h}$. The reaction system was stable at room temperature. However, after $30 \mathrm{~min}$, when sodium hydroxide solution was added to the deep-red colored solution of the complex solution, a deep-blue color of the complex was developed unstably with increased absorbance. Thus, the absorbance of cyanide-ninhydrin complex (red color) was determined with the incubation time about 30 min before adding of sodium hydroxide solution.

Aqueous micellar media are widely used in many areas of analytical chemistry and several 
reviews concerning their analytical applications have been published. One important property of micelles is their soluble ability of a wide variety of compounds which are insoluble or slightly soluble in water. It might also be expected that the sensitivity of the complex may increase due to stability of the complex forming in micellar medium. The absorbance of the cyanide-ninhydrin complex was, thus, studied in the presence of different aqueous micellar environments including Triton X-100, CTAB, SDS and Tween 20. Comparison of the kinetics of the absorbance showed less difference in the micellarmedia. However, 1\% (v/v) Tween 20 was found to give better result.

The influence of an increasing the concentration of micellar media (Tween 20) on the absorbance was also investigated. It was found that the absorbance was stable with an increase in the amount of Tween 20. Thus, an addition of 400 $\mu \mathrm{L}$ of $1 \%(\mathrm{v} / \mathrm{v})$ Tween 20 was used throughout the experiments.

In addition, to investigate the reagent adding sequence it was found that the difference in adding sequences affected the absorbance slightly (data not shown). In any case, the adding of $\mathrm{NaOH}$ solution at the final step could give higher absorbance for the studied system compared with the first adding step of $\mathrm{NaOH}$ solution.

A systematic study of the interference of foreign ions in the determination of cyanide $(0.12$ $\mathrm{mg} / \mathrm{L}$ ) was carried out. For this study, the effect of foreign species commonly found in association with cyanide ion was studied by adding known amounts of diverse ions to the standard cyanide solution. If it interfered, the ratio was gradually reduced until the interference ceased. The criterion for the interference was fixed at $\pm 2 \%$ variation of the average absorbance, calculated for the established level of cyanide. The results are given in Table 3.

The interfering effects of common anions and cations, which may co-exist with cyanide, were studied. In the free cyanide determination, varying concentration of the interfering species was introduced into $0.12 \mathrm{mg} / \mathrm{L}$, and the recovery of cyanide was established following the procedure described under the determination of free cyanide.
In the present method, silver and mercuric ions also interfere with cyanide determination, making precipitates with the ninhydrin reagent.

In order to evaluate the potential of the present method for quantitative uses, linearity, LOD and $L O Q$, precision and recovery were investigated.

\section{Linearity, LOD and LOQ}

According to the proposed method, the calibration curve for the determination of cyanide was constructed under the optimum conditions. The linear range for cyanide was 0.04 to $0.16 \mathrm{mg} / \mathrm{L}$ and the linear regression equation was as follows: $Y=$ $8.395 X-0.0845(\mathrm{mg} / \mathrm{L})$, with a correlation coefficient $\left(r^{2}\right)$ greater than 0.99 .

Both LOD and LOQ of the present method were deduced based on the concentration of cyanide which produced an analytical signal for three times and ten times of the standard deviation of the background signal ( $\mathrm{S} / \mathrm{N}=3$ and 10 ) of blank measurements $(n=10)$, as defined by IUPAC, were 0.01 and $0.02 \mathrm{mg} / \mathrm{L}$, respectively.

\section{Precision and Recovery}

The repeatability and reproducibility were investigated in terms of relative standard deviation (RSD). The repeatability (intra-day precision, $n=$ 3 ) and reproducibility (inter-day precision, $n=5$ ) of the calibration slopes were also obtained. Table 4 shows the intra-day precision and inter-day precision in which the percentages of RSD were 0.91 and 4.44 , respectively. The recovery was studied by spiking $250 \mu \mathrm{g} / \mathrm{L}$ of cyanide ion into wine samples after preparation by micro-distillation and analysis by spectrophotometry. The percentage recoveries of free, bound and total cyanide for all types of the sample matrices were found in the range of 76.2$89.2 \%, 73.2-91.2 \%$ and $76.8-94.8 \%$, respectively as summarized in Table 5.

The developed method was applied to the determination of residual cyanide in different types of wine samples which comprised of the different matrices. The content of cyanide was found to be less than its detection limit (data not shown). It could therefore be noted that there was no residual cyanide found as a background contaminant in the 
wine samples used. Accordingly, it is shown that this method offers simple and accurate procedure for the determination of cyanide based on the complexation with ninhydrin prior to measurement by such a common spectrophotometry. The validated method was successfully applied to determine the cyanide at ultra-trace level in the wine samples.

\section{Determination of cyanide by chloramine-T/ barbituric acid-pyridine}

This experiment was also carried out for the determination of cyanide according to the standard method using chloramine-T/barbituric acid-pyridine method. The reagents for this cyanide determination were composed of potassium hydrogen phthalate buffer, chloramine-T solution and barbituric acidpyridine. Finally, the solution was diluted to $10 \mathrm{~mL}$ volumetric flask by deionized water and measured spectrophotometrically at $600 \mathrm{~nm}^{17,22,28}$.

The analytical performance of the standard method was evaluated using the optimum conditions. Calibration plot, LOD and LOQ, precision and recovery were also investigated as well.

\section{Calibration graph, LOD and LOQ}

Calibration curve was constructed between 0.2 and $1.2 \mathrm{mg} / \mathrm{L}$ and linear regression equation was as $Y=0.9172 X+0.0148(\mathrm{mg} / \mathrm{L})$, with a correlation coefficient $\left(r^{2}\right)$ of 0.9992 . Both LOD and LOQ were calculated as $3 \mathrm{SD} / \mathrm{S}$ and $10 \mathrm{SD} / \mathrm{S}$, respectively; where SD is the blank standard deviation and $S$ is the sensitivity of the method calculated as the calibration slope $^{29}$. LOD and LOQ of the standard method were 0.02 and $0.11 \mathrm{mg} / \mathrm{L}$, respectively.

\section{Precision and Recovery}

Precision of the standard method is expressed in terms of relative standard deviation (RSD), estimated from 3 replicates (intra-day) and 10 replicates (inter-day). Table 6 shows the intraday precision and inter-day precision in which the percentages of RSD were 0.32 and 4.57 , respectively. Recovery was studied by spiking the $250 \mu \mathrm{g} / \mathrm{L}$ of cyanide in wine samples before preparation and was determined by the standard method. The percentage recoveries of free, bound and total cyanide for all types of the sample matrices were found in the range of $75.4-89.4 \%, 73.9-90.7 \%$ and $75.1-92.9 \%$, respectively as summarized in Table 7 .
The standard method was applied for the determination of residual cyanide in different sample matrices including white wine and red wine. The contents of cyanide were also not detectable in white wine and red wine samples (data not shown). It is shown that, in this case, the determination of cyanide in these wine samples could also be carried out by the standard method for both free cyanide and bound cyanide spiked at trace level in the wine samples.

In comparison, the results obtained from using ninhydrin reagent following the micro-distillation were compared with those of the standard method used as a reference method in terms of Student's $t$-test. The student's $t$-test shows that no statistically significant difference at $95 \%$ confidence level was found between the two methods.

\section{CONCLUSION}

Sample preparation and trace analysis of cyanide based on the absorbance of the catalytic reaction of ninhydrin in the presence of cyanide following micro-distillation of free and bound cyanide was developed. The distillate containing cyanide ion was kept in base solution and then determined spectrophotometrically. The optimum conditions of the catalytic reaction of ninhydrin were investigated in detail including $\mathrm{pH}$ and buffering system, concentrations of ninhydrin, sodium carbonate and sodium hydroxide, reaction time and types of micellar media. The method could be applied for the determination of residual cyanide in wine samples. No trace amount of cyanide was, however, detected in the distillate of the samples in association with relatively high recovery $(88.4 \%)$ of the microdistillation efficiency. The results obtained were in agreement with those of chloramine-T/barbituric acid-pyridine method with no statistically significant difference at $95 \%$ confidence level. The developed analytical method is useful as a routine alternative choice for the trace determination of cyanide.

\section{ACKNOWLEDGEMENTS}

Research financial support from the Center of Excellence for Innovation in Chemistry (PERCH$\mathrm{CIC})$, Commission on Higher Education, Ministry of Education, Thailand and the Hitachi Scholarship Foundation, Tokyo, Japan is gratefully acknowledged. 


\section{REFERENCES}

1. Lara, R., Cerutti, S., Salonia, J.A., Olsina, R.A. and Martinez, L.D., Food Chem. Toxicol., 43: 293-297 (2005).

2. Šperková J. and Suchánek, M., Food Chem., 93: 659-663 (2005).

3. Chanthai, S., Suwamat, N., Ruangviriyachai, C and Danvirutai, P., ASEAN Food J., 14(3): 181-196 (2007).

4. Wine \& Beverage Standards, ed. Bell, D.A., Van Nostrand Reinhold, New York, 1989.

5. Galani-Nikolakaki, S., Kallithrakas-Kontos, N. and Katsanos, A.A., Sci. Total Environ., 285: 155-163 (2002).

6. Stafilov, T and Karadjova, I., Int. J. Pure Appl. Chem., 1(2): 273-305 (2006).

7. Bates, B.L. and Buick, D.R., J. Assoc. Off. Anal. Chem., 59(6): 1390-1395 (1976).

8. Tina, B.H., Leif, H.S. and Henrik, J.A., Meat Sci., 43(2): 135-144 (1995).

9. Yong-Lai, F., Hisatake, N., Li-Ching, T., SaoMing, W. and Hong-Yuan, C., Anal. Chem., 15: $915-918$ (1999).

10. Rezaul, M.H. and Howard, J.B., Food. Chem., 77: 107-114 (2002).

11. Jean-Louis, R. and Jean-Marie, S., J. Biosci. Bioeng., 96(5): 434-437 (2003).

12. V. Goel, Orient J. Chem., 28(4): 1725-1728 (2012).

13. A. Daneshfar, F. Ansari and S. Hasanvandi, Orient J. Chem., 28(1): 89-96 (2012).

14. Ramachandram, B., Joseph, R.L. and Chris, D.G., Dyes Pigments, 64: 49-55 (2005).

15. Labat, L., Dumestre-Toulet, V., Goulle, J.P. and Lhermitte, M., J. Forensic Sci., 143: 215-217 (2004).

16. Focus on pigments: Ferrocyanide, Japan
Chemical Week, 45(2251): 2 (2004).

17. David, D.H. and Thomas, C.Y., Chemosphere, 60: 1222-1230 (2005).

18. Jiagen, L., Zhujun, Z., Jindong, L. and Lirong, L., J. Forensic. Sci., 148: 15-19 (2005).

19. AOAC Official Methods of Analysis. AOAC official method 973.19 cyanide in liquors and wine, 28: 13-17 (2000).

20. Maria, T.F.A. Jose', M.C.F., Rosario, P. and Alfredo, S.M., Anal. Chim. Acta, 2003, 491: 27-35 (2003).

21. Satochi, C. and Nariaki, T., Japanese J. Sci. Technol. Identific., 2(1): 27-31 (1997).

22. James, A.C. Heather, L.N. and Robert, M.M., J. Chromatogr. A, 739: 229-232 (1996).

23. Manuel, A., Adriana, F. and Vicenc, M., Anal. Chem., 363: 121-123 (1999).

24. Tim, M. and Heidi, B., Anal. Chim. Acta, 406: 283-288 (2000).

25. Tomada. A. and Hashimoto, K., J. Hazard. Mater., 28(3): 241-249 (1991).

26. Shigeru, N., Anal. Chim. Acta, 91(2): 303-306 (1977).

27. Mendel, F., J. Agric. Food. Chem., 52:385-406 (2004).

28. Padmarajaiah, N., Mattighatta, S.H.K., Hemmige, S.Y. and Jainara, S.P., Anal. Sci., 18: 1027-1030 (2002).

29. Tim, M and Heidi, B., Anal. Chim. Acta, 435: 377-384 (2001).

30. Hayashi, Y., Matsuda, R., Ito, K., Nishimura, W., Imai, K. and Maeda, M., Anal. Sci., 21: 167-169 (2005).

31. Li, J., He, F. and Jiang, C., Anal. Sci., 22: 607611 (2006). 